IRA-International Journal of Applied Sciences ISSN 2455-4499; Vol.04, Issue 03 (2016)

Institute of Research Advances

Pg. no. 541-552

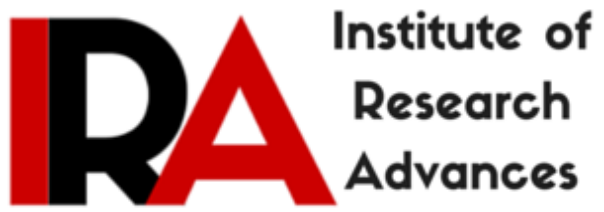

http://research-advances.org/index.php/IRAJAS

\title{
Relationship of Maternal Depression during Pregnancy and Risk of Preeclampsia
}

\author{
Sharda Ghoghre ${ }^{1} \&$ Tara Singh ${ }^{2}$ \\ ${ }^{1}$ Assistant Prof., Department of Psychology, \\ Govt. Kirodimal Arts \& Science College, Raigarh, Chattisgarh, India. \\ ${ }^{2}$ Professor, Department of Psychology, Banaras Hindu University, Varanasi, Uttar \\ Pradesh, India.
}

Type of Review: Peer Reviewed.

DOI: http://dx.doi.org/10.21013/jas.v4.n3.p17

\section{How to cite this paper:}

Ghoghre, S., \& Singh, T. (2016). Relationship of Maternal Depression during Pregnancy and Risk of Preeclampsia. IRA-International Journal of Applied Sciences (ISSN 2455-4499), 4(3), 541-552. doi:http://dx.doi.org/10.21013/jas.v4.n3.p17

(C) Institute of Research Advances

\section{(cc) EY-NC}

This work is licensed under a Creative Commons Attribution-Non Commercial 4.0 International License subject to proper citation to the publication source of the work.

Disclaimer: The scholarly papers as reviewed and published by the Institute of Research Advances (IRA) are the views and opinions of their respective authors and are not the views or opinions of the IRA. The IRA disclaims of any harm or loss caused due to the published content to any party. 


\section{ABSTRACT}

Present research paper investigates the relationship of maternal depression during pregnancy and risk of preeclampsia. It is a cross sectional study conducted on 200 pregnant women from different maternity homes in Betul \& Bhopal District from Madhya Pradesh. IDAS scale was used to see the depression level among pregnant women having preeclampsia or without preeclampsia. For analysis of data One way analysis of variance was used to show the significant relationship between depression and risk of Preeclampsia among pregnant women having preeclampsia and without preeclampsia. The results of the study show significant relationship of depression among pregnant women having preeclampsia and without preeclampsia.

KEYWORDS: Preeclampsia, Depression, Hypertension, Proteinuria

\section{INTRODUCTION}

Hypertensive disorder of pregnancy, including gestational hypertension and preeclampsia, are responsible for $12-15 \%$ of pregnancy related deaths worldwide (World health report, 2005) and are leading cause of premature delivery (Pschirrer \& Monga, 2000). Preeclampsia is defined by sustained pregnancy induced hypertension with proteinuria (National High Blood Pressure Education Program, 2000). The origin of hypertensive disorders during pregnancy are not clearly delineated, but multiple factors are implicated. Depression, stress and anxiety appear to contribute to risk. Psychological factors including self image, self health, well being of the fetus, labor and delivery, relationship with the spouses and economic status of the family are the contributing factors that exuberated the depression and anxiety level among pregnant women.

\section{CURRENT CONCEPTS}

Pregnancy is often considered one of the happiest times in a woman's life. But pregnancy isn't always such a happy time. It is often filled with stress and worry as well as numerous emotional upheavals and physical changes. As a result, many pregnant women develop depression during their pregnancies. Depression, is define by the American Psychiatric Association (APA) as "a depressed mood or a loss of pleasure in nearly all normal activities for a period of at least two weeks (Gray BA, 2006)," in combination with the presence of at least four of the following symptoms: alteration in normal appetite or weight, change in sleep and activity, energy, thoughts or feelings of worthlessness or guilt, difficulty with decision making, attention or thinking, or, recurrent thoughts, plans, or attempts at suicide ( American Psychological Association ,2002).

It is well known that women of childbearing age often suffer from anxiety and depression (Wisner et al., 2000). Estimates of lifetime risk in community-driven samples of pregnant women vary between 10\% and 25\% (Wisner et al., 2000; Nonacs \& Cohen, 2002; Burt \& Stein, 2002). The research examine risk of untreated anxiety and depression during pregnancy suggests that psychopathologic symptoms during pregnancy have physiological consequences for fetuses (Kurki et al., 2000) it has also been postulated that anxiety and depression result in hazardous behaviours that can indirectly affect obstetric outcomes. Studies have found that mental illness can affect a mother's functional status and her ability to obtain prenatal care and avoid dangerous behaviour. Mental illness can also affect decisionmaking capacities by causing cognitive distortions, and because of this it has been associated with poor attendance at antenatal clinics and malnutrition which could lead to low birth weight babies (Evans et al., 2001). Depression and anxiety in pregnancy may also compromise a women's physical and mental health and the health of her unborn baby through diminishing her capacity for self-care including inadequate nutrition, increased drug or alcohol abuse and poor antenatal clinic attendance (Austin, 2003).

Depressed women are more likely to smoke and use alcohol or other substances, which might compromise pregnancy. Depressed women can show deteriorating social function, emotional withdrawal, 
and excessive concern about their future ability to parent. They report excessive worry about pregnancy, are less likely to attend regular obstetric visits, and do not comply with prenatal advice. They take prenatal vitamins less often than non-depressed women and know less about the benefits of folic acid (Nonacs \& Cohen, 2002; Burt \& Stein, 2002; Zuckerman et al., 2001). Severe depression also carries the risk of self-injurious, psychotic, impulsive, and harmful behaviors that can affect pregnancy.

Untreated depression and anxiety during pregnancy has been linked to other adverse outcomes, such as spontaneous abortion (Arck, 2001; Sugiura-Ogasawara et al., 2002), increased uterine artery resistance (Teixeira, Fisk, \& Glover, 1999), small head circumference, low ApGAR scores, need for special neonatal care, neonatal growth retardation, preterm delivery, and babies with high cortisol levels at birth (Wisner et al., 2000' Nonacs \& Cohen, 2002; Kurki et al., 2000; Evans et al., 2001; Zuckerman et al., 1989; Chung et al., 2001; Ashman et al., 2002; Orr \& Miller, 1995; Steer et al., 1992). Studies also suggest that pregnant women who are depressed require more operative deliveries and report labor as more painful, which means they require more epidural analgesia. Gestational hypertension and subsequent pre-eclampsia has also been linked to untreated depression during pregnancy. Psychopathology during pregnancy is thought to affect the uterine environment and, therefore, could have an effect on fetal outcome. Current theories suggest that depression increases excretion of vasoactive hormones in the mother, and these hormones then mediate birth outcome.

\section{METHODOLOGY}

\section{Sample}

A cross sectional study was conducted on $200(\mathrm{n}=200)$ pregnant women. The study was conducted in the obstetric wards of hospital of Madhya Pradesh. Mainly two districts; were taken in the study; Bhopal and Betul. The sample includes one hundred cases of pregnant women with preeclampsia and hypertensive disorders. Preeclampsia cases was identified by daily monitoring of all new admission to ante partum wards, emergency wards and labor room and delivery wards of the hospitals. Control group consisted women without preeclampsia, uncomplicated by pregnancy induced hypertension or proteinuria. It comprises of 100 pregnant women without preeclampsia and hypertensive disorder matched on age, educational level, marital status, family type, income and other relevant variables. This was a cross sectional study and the sampling technique was of convenience sampling. The study was spread over a period of more than one year (2007-09).

\section{Design}

In order to examine the relationships of different measure, a cross sectional design was used. One way analysis of variance was used to see the significant relationship between groups on the measure of depression.

\section{Tool}

IDAS scale is used to measures reliably outwardly directed and inwardly directed depression, anxiety and irritability developed by Snaith et al, 1978 .

\section{Procedure}

Different maternity homes and hospital of Betul and Bhopal were listed. Then the permission was taken from the higher authority to conduct this research. After that participants having preeclampsia or without preeclampsia were selected, then consent was taken from them. In a quiet place (Doctors duty room) sitting arrangement was done, after that good rapport was established with the participants, necessary instructions and guidelines were provided to them for properly responding the questionnaire. The purpose of the study was explained and participants were assured that their responses will be kept confidential and will be used for research and academic purpose only. After this, question were asked to them and requested to give answer as per the instructions provided to them. After that we thanks to participants for heartily cooperation to complete their questionnaire. All other necessary information 
regarding participants was also collected from hospital staff and hospital record book.

\section{Socio Demographic characteristics of sample}

Table 1 shows the demographic and personal characteristics of pregnant women. The total number of participants $(\mathrm{n}=200)$. The number and percentage of women with preeclampsia (Patient) $(\mathrm{n}=$ $100, \%=50)$ and women without preeclampsia $(\mathrm{n}=100, \%=50)$. Participants ranged in age from 18 to35 years. Mean and SD scores for age in patient group $(\mathrm{M}=1.12, \mathrm{SD}=0.33)$, most of the patient are between age range of 18 to 25 years $(\mathrm{n}=88, \%=88)$. Number and percentage of patient who are between age range of 26 to 35 years $(\mathrm{n}=12, \%=12)$. In control group mean and SD scores for age $(\mathrm{M}=1.27, \mathrm{SD}$ $=0.45)$, most of the normal pregnant women are between age range of 18 to 25 years $(\mathrm{n}=73, \%=73)$. Number and percentage of control group, between the age range of 26 to 35 years $(n=27, \%=27)$. In both the groups, most of the participants are between age ranges of 18 to 25 years

Mean and SD scores for religion in patient group $(\mathrm{M}=1.10, \mathrm{SD}=0.30)$. Number and percentage of Hindu $(\mathrm{n}=90, \%=90)$ and Muslim $(\mathrm{n}=10, \%=10)$ in patient group. Most of the patients belong to Hindu families which suffer from preeclampsia. In control group mean and SD scores for religion $(\mathrm{M}=$ $1.20, \mathrm{SD}=0.55)$, most of the normal pregnant women belongs to Hindu families $(\mathrm{n}=85, \%=85)$. Number and percentage of Muslims pregnant women in control group $(\mathrm{n}=15, \%=15)$. In both the group Hindu participants are more in comparison to other religion women.

Table:1 Demographic characteristics of pregnant women with preeclampsia or without preeclampsia

\begin{tabular}{|c|c|c|c|c|c|c|c|c|}
\hline \multirow[t]{2}{*}{ Variables } & \multicolumn{4}{|c|}{ Patient $(n=100)$} & \multicolumn{4}{|c|}{ Control $(n=100)$} \\
\hline & $N$ & $\%$ & $M$ & $\bar{S} D$ & $N$ & $\%$ & $M$ & $S D$ \\
\hline \multicolumn{9}{|c|}{ Socio-demographic variables } \\
\hline \multicolumn{9}{|c|}{ Age } \\
\hline \multicolumn{9}{|l|}{$18-25$} \\
\hline \multirow[t]{2}{*}{$26-35$} & 88 & 88.0 & 1.12 & 0.33 & 73 & 73.0 & 1.27 & 0.45 \\
\hline & 12 & 12.0 & & & 27 & 27.0 & & \\
\hline \multicolumn{9}{|l|}{ Religion } \\
\hline Hindu & 90 & 90.0 & & & 85 & 85.0 & & \\
\hline Muslim & 10 & 10.0 & 1.10 & 0.30 & 12 & 12.0 & 1.20 & 0.55 \\
\hline Others & - & - & & & 3 & 3.0 & & \\
\hline \multicolumn{9}{|l|}{ Caste } \\
\hline Schedule tribe & 25 & 25.0 & & & 27 & 27.0 & & \\
\hline Schedule Cast & 18 & 18.0 & & & 26 & 26.0 & & \\
\hline Other backward class & 51 & 51.0 & 2.38 & 0.98 & 41 & 41.0 & 2.26 & 0.93 \\
\hline General & 6 & 6.0 & & & 6 & 6.0 & & \\
\hline \multicolumn{9}{|l|}{ Residence } \\
\hline Urban & 12 & 12.0 & & & 19 & 19.0 & & \\
\hline Rural & 88 & 88.0 & 1.89 & 0.35 & 81 & 81.0 & 1.86 & 0.47 \\
\hline \multicolumn{9}{|l|}{ Education } \\
\hline Illiterate & 27 & 27.0 & & & 32 & 32.0 & & \\
\hline Primary & 39 & 39.0 & & & 9 & 9.0 & & \\
\hline Secondary & 18 & 18.0 & 1.30 & 1.19 & 28 & 28.0 & 1.76 & 1.52 \\
\hline Higher Secondary & 11 & 11.0 & & & 18 & 18.0 & & \\
\hline Under Graduate & 4 & 4.0 & & & 9 & 9.0 & & \\
\hline Post Graduate & 1 & 1.0 & & & 4 & 4.0 & & \\
\hline
\end{tabular}




$\begin{array}{lllllllll}\text { Working Status } & & & & & & & & \\ \quad \text { Working } & 71 & 71.0 & & & 8 & 8.0 & & \\ \quad \text { Non working } & 29 & 29.0 & 1.29 & 0.46 & 92 & 92.0 & 1.92 & 0.27 \\ \quad \text { Income } & & & & & & & & \\ \quad \text { Low }(10000-70000) & 41 & 41.0 & & & 31 & 31.0 & & \\ \quad \text { Moderate(75000-90000) } & 23 & 23.0 & 2.45 & 0.85 & 42 & 42.0 & 1.53 & 0.59 \\ \quad \text { High }(100000-500000) & 20 & 20.0 & & & 27 & 27.0 & & \\ \quad \begin{array}{l}\text { Family type } \\ \quad \text { Nuclear }\end{array} & 73 & 73.0 & & & & & & \\ \quad \text { Joint } & 27 & 27.0 & 1.73 & 0.45 & 81 & 81.0 & 1.81 & 0.39\end{array}$

Mean and SD scores for Category/caste in patient group $(\mathrm{M}=2.38, \mathrm{SD}=0.93)$. Number and percentage of schedule tribe $(\mathrm{n}=25, \%=25)$, schedule caste $(\mathrm{n}=18, \%=18)$, other backward class $(\mathrm{n}=51, \%=51)$ and General $(\mathrm{n}=6, \%=6)$ in patient group. Mean and SD scores for category/caste in control group $(\mathrm{M}=$ $2.26, \mathrm{SD}=0.93)$. Number and percentage of schedule tribe $(\mathrm{n}=27, \%=27)$, schedule caste $(\mathrm{n}=26, \%=$ $26)$, other backward class $(n=41, \%=41)$ and General $(n=6, \%=6)$ in control group. Most of the women are from other backward class in comparison to other category in group, fewer women from General category. Mean scores indicated that in some extent it effect preeclampsia in groups.

Mean and SD scores for residence in patient group $(\mathrm{M}=1.89, \mathrm{SD}=0.35)$, most of the patient from rural area $(\mathrm{n}=88, \%=88)$ and less patient from urban area $(\mathrm{n}=12, \%=12)$. Mean and SD scores for residence in control group $(\mathrm{M}=1.86, \mathrm{SD}=0.47)$, most women belongs to rural area $(\mathrm{n}=81, \%=81)$, and less women in control group from urban area $(\mathrm{n}=19, \%=19)$. It also indicated that it not affect preeclampsia.

Mean and SD scores for working status in patient group $(\mathrm{M}=1.29, \mathrm{SD}=0.35)$. Here most of the women are working having preeclampsia $(\mathrm{n}=71, \%=71)$. Less women are non- working $(\mathrm{n}=29, \%=$ 29). Mean and SD scores for working status in control group $(\mathrm{M}=1.92, \mathrm{SD}=0.27)$. Here less of the women are working having no preeclampsia $(\mathrm{n}=8, \%=8)$. Most women are non- working $(\mathrm{n}=92, \%=$ 92).Mean scores indicated that it affect preeclampsia because in patient group most of the women are working. They are having work stress and responsibility of home; it was not easy to manage between work and home responsibilities.

Mean and SD scores for income in patient group $(\mathrm{M}=2.45, \mathrm{SD}=0.85)$. Most of the women had low income $(\mathrm{n}=41, \%=41)$. Number and percentage of moderate $(\mathrm{n}=23, \%=23)$ and high income $(\mathrm{n}=$ $20, \%=20)$ are less in compare to low income. But in control group mean scores and SD for income (M $=1.53, \mathrm{SD}=0.59)$. Number and percentage for low income $(\mathrm{n}=31, \%=31)$, moderate $(\mathrm{n}=42, \%=42)$ and high income $(\mathrm{n}=27, \%=27)$. Moderate income women are more in comparison to low and high income women in control group. Mean score indicated that income effect preeclampsia because most of the women in patient group having low income; it was not easy for them to manage expenses of hospital.

Mean and SD scores for family type in patient group $(\mathrm{M}=1.73, \mathrm{SD}=0.45)$. Number and percentage of family type, most of the patient belong to nuclear family $(\mathrm{n}=73, \%=73)$ than the joint family $(\mathrm{n}=27, \%=27)$.In control group mean score and $\mathrm{SD}(\mathrm{M}=1.81, \mathrm{SD}=0.86)$. Number and percentage of family type, most of the normal pregnant women belong to joint family $(\mathrm{n}=81, \%=81$ ) than the nuclear family $(\mathrm{n}=19, \%=19)$. 


\section{Biomedical characteristic of the pregnant women having preeclampsia and normal pregnant women}

To examine relationship between biomedical variable and preeclampsia number, Percentage, mean score and SD were taken. Table 2 represents the biomedical characteristics of pregnant women. Mean and SD scores for numbers of children $(\mathrm{M}=0.44, \mathrm{SD}=0.88)$. Most of the patients are having no children. Number and percentage of women with preeclampsia who had no child $(\mathrm{n}=73, \%=73)$. Women with preeclampsia those having one child $(\mathrm{n}=17, \%=17)$, two child $(\mathrm{n}=5, \%=5)$, and $3+(\mathrm{n}=$ $5, \%=5)$. In control group mean and SD scores for numbers of children $(\mathrm{M}=0.53, \mathrm{SD}=0.88)$. Number and percentage of numbers of children in control group with no child $(n=62, \%=62)$, one child $(n=28$, $\%=28)$, two children $(\mathrm{n}=8, \%=8)$ and $3+(\mathrm{n}=2, \%=2)$. There was little difference in mean scores; we cannot say it affects preeclampsia.

Mean and SD scores for parity in patient group $(\mathrm{M}=1.41, \mathrm{SD}=0.91)$. Number and percentage for parity in patient group with zero parity $(\mathrm{n}=3, \%=3)$, one $(\mathrm{n}=70, \%=70)$, two $(\mathrm{n}=17, \%=17)$, three $(\mathrm{n}=5, \%=5)$ and four $(\mathrm{n}=5, \%=5)$. In control group Mean and SD scores for parity $(\mathrm{M}=1.54$, $\mathrm{SD}=0.86)$. Number and percentage for parity in control group with zero parity $(\mathrm{n}=0, \%=0)$, one $(\mathrm{n}=$ $61, \%=61)$, two $(\mathrm{n}=29, \%=29)$, three $(\mathrm{n}=8, \%=8)$ and four $(\mathrm{n}=2, \%=2)$. It indicated that it's not effect preeclampsia. Mean and SD scores for age of the previous child in patient group $(\mathrm{M}=0.76, \mathrm{SD}=$ 1.28). Number and percentage for age of previous child in patient group with no child $(\mathrm{n}=73, \%=73)$, one year six month $(\mathrm{n}=00, \%=00)$, two years $(\mathrm{n}=8, \%=8)$, two year six month $(\mathrm{n}=1, \%=1)$, three years $(\mathrm{n}=15, \%=15)$ and four years $(\mathrm{n}=3, \%=3)$.

Mean and SD scores for age of the previous child in control group $(\mathrm{M}=0.82, \mathrm{SD}=1.09)$. Number and percentage for age of previous child in control group with no child $(\mathrm{n}=62, \%=62)$, one year six month $(\mathrm{n}=7, \%=7)$, two years $(\mathrm{n}=21, \%=21)$, two year six month $(\mathrm{n}=1, \%=1)$, three years $(\mathrm{n}=9, \%=9)$ and four years $(\mathrm{n}=0, \%=0)$.

Mean and SD scores for gestational age in patient group $(\mathrm{M}=2.53, \mathrm{SD}=0.98)$. Number and percentage for gestational age in patient group $<30(\mathrm{n}=44, \%=44), 30$ to 33 gestational age $(\mathrm{n}=25, \%=$ $25)$ and 34 and above $(\mathrm{n}=31, \%=31)$. Mean and SD scores for gestational age in control group $(\mathrm{M}=$ $2.12, \mathrm{SD}=0.46)$. Number and percentage for gestational age in control group $<30(\mathrm{n}=37, \%=37), 30$ to 33 gestational age $(\mathrm{n}=46, \%=46)$ and 34 and above $(\mathrm{n}=17, \%=17)$. Mean scores indicate that it affect preeclampsia.

Table 2:

Biomedical characteristics of pregnant women with preeclampsia or without preeclampsia

\begin{tabular}{lllllllll} 
Variables & \multicolumn{3}{c}{ Patient $(\boldsymbol{N}=\mathbf{1 0 0})$} & \multicolumn{4}{c}{ Control $(\boldsymbol{N}=\mathbf{1 0 0})$} \\
\cline { 2 - 9 } & $\boldsymbol{N}$ & $\boldsymbol{\%}$ & $\boldsymbol{M}$ & $\boldsymbol{S D}$ & $\boldsymbol{N}$ & $\boldsymbol{\%}$ & $\boldsymbol{M}$ & $\boldsymbol{S D}$ \\
\hline No. of children & & & & & & & & \\
0 & 73 & 73.0 & & & 62 & 62.0 & & \\
1 & 17 & 17.0 & 0.44 & 0.88 & 28 & 28.0 & 0.53 & 0.88 \\
2 & 5 & 5 & & & 8 & 8.0 & & \\
$3+$ & 5 & 5 & & & 2 & 2.0 & &
\end{tabular}




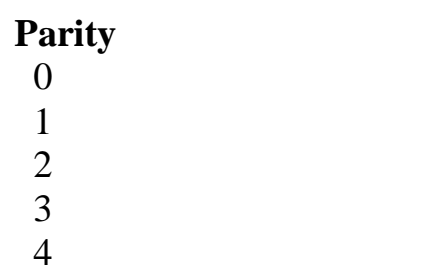

\section{Age of the previous child}

No child

1 year 6 month

2 years

2year 6 month

3 years

4 years

\section{Gestational Age}

$<30$

30-33

34 and above

Systolic

Normal

Prehypertension

Stage 1

Stage 2

Diastolic

Normal

Prehypertension

Stage 1

Stage 2

\section{Proteinuria}

Nil

$1+$

$2+$

$\begin{array}{ll}3 & 3.0 \\ 70 & 70 \\ 17 & 17 \\ 5 & 5.0 \\ 5 & 5.0\end{array}$

$\begin{array}{ll}73 & 73.0\end{array}$

0

1

15

3

0.0

8.0

1.0

15.0

3.0

$44 \quad 44.0$

$25 \quad 25.0$

31

31.0

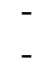

84

16

-

$-$

84.0

16.0

- $\quad-$

-

67

33

67.0

33.0

$\begin{array}{llllll} & & 0 & 0.0 & & \\ & & 61 & 61.0 & & \\ 1.41 & 0.91 & 29 & 29.0 & 1.54 & 0.86 \\ & & 8 & 8.0 & & \\ & & 2 & 2.0 & & \end{array}$

$62 \quad 62.0$

$\begin{array}{lll}7 & 7.0\end{array}$

$\begin{array}{llll}0.76 & 1.28 & 21 & 21.0\end{array}$

$0.82 \quad 1.09$

$1 \quad 1.0$

99.0

0.0

\begin{tabular}{|c|c|c|c|c|c|}
\hline \multirow{3}{*}{2.53} & & 37 & 37.0 & \multirow{3}{*}{2.12} & \multirow{3}{*}{0.46} \\
\hline & 0.98 & 46 & 46.0 & & \\
\hline & & 17 & 17.0 & & \\
\hline \multirow{5}{*}{3.16} & & 89 & 89.0 & \multirow{6}{*}{1.11} & \multirow{6}{*}{0.31} \\
\hline & & 11 & 11.0 & & \\
\hline & 0.37 & - & - & & \\
\hline & & - & - & & \\
\hline & & 80 & 80.0 & & \\
\hline \multirow[b]{2}{*}{7.33} & & 3 & 3.0 & & \\
\hline & 0.47 & 17 & 17.0 & 5.37 & 0.76 \\
\hline
\end{tabular}

$\begin{array}{ll}- & - \\ 84 & 84.0 \\ 16 & 16.0\end{array}$

$\begin{array}{lllllll}2.16 & 1.36 & - & - & 100 & 100 & \\ & & - & - & & & \\ & & & & & & \end{array}$

Mean and SD scores for systolic blood pressure in patient group $(M=3.16, S D=0.37)$. Number and percentage for systolic blood pressure in patient group normal blood pressure $(\mathrm{n}=00, \%=00)$, prehypertension $(\mathrm{n}=0, \%=0)$, stage $1(\mathrm{n}=84, \%=84)$ and stage $2(\mathrm{n}=16, \%=16)$. Mean and SD scores for systolic blood pressure in control group $(\mathrm{M}=1.11, \mathrm{SD}=0.31)$. Number and percentage for systolic blood pressure in control group normal blood pressure $(\mathrm{n}=89, \%=89)$, pre-hypertension $(\mathrm{n}=11, \%=$ $11)$, stage $1(\mathrm{n}=0, \%=0)$ and stage $2(\mathrm{n}=0, \%=0)$. Mean scores indicate that patient having high systolic blood pressure in comparison to control. It is because of high systolic blood pressure was the essential feature of preeclampsia.

The Mean and SD scores for diastolic blood pressure in patient group $(\mathrm{M}=7.33, \mathrm{SD}=0.47)$. Number and percentage for diastolic blood pressure in patient group normal blood pressure $(\mathrm{n}=00, \%=$ $00)$, pre-hypertension $(\mathrm{n}=0, \%=0)$, stage $1(\mathrm{n}=67, \%=67)$ and stage $2(\mathrm{n}=33, \%=33)$. Mean and SD scores for diastolic blood pressure in control group $(\mathrm{M}=5.37, \mathrm{SD}=0.76)$. Number and percentage for diastolic blood pressure in control group normal blood pressure $(\mathrm{n}=80, \%=80)$, pre-hypertension $(\mathrm{n}=3$, 
$\%=3)$, stage $1(\mathrm{n}=17, \%=17)$ and stage $2(\mathrm{n}=0, \%=0)$. Here also the diastolic blood pressure was high among patient group, high diastolic blood pressure is the keynote feature of preeclampsia.

Mean and SD scores for proteinuria $(\mathrm{M}=2.16, \mathrm{SD}=1.36)$. Number and percentage of proteinuria in patient group $1+(\mathrm{n}=84, \%=84)$ and $2+(\mathrm{n}=16, \%=16)$. Mean and SD scores for proteinuria in control group $(\mathrm{M}=1.0, \mathrm{SD}=0.0)$. Number and percentage of absence of proteinuria in control group $(\mathrm{n}=100, \%=100)$. Mean score indicate that proteinuria was more in patient group because proteinuria was the essential feature of preeclampsia.

Mean and SD scores for BMI in patient group $(\mathrm{M}=2.53, \mathrm{SD}=0.98)$. Number and percentage of BMI in patient group < $19.1(\mathrm{n}=11, \%=11), 19.1$ to $25.8(\mathrm{n}=49, \%=49), 25.8$ to $27.3(\mathrm{n}=16, \%=16)$, 27.3 to $32.3(\mathrm{n}=24, \%=24)$ and $>32.3(\mathrm{n}=0, \%=0)$. Mean and SD scores for BMI in control group (M $=2.12, \mathrm{SD}=0.46)$. Number and percentage of BMI in control group < $19.1(\mathrm{n}=1, \%=1), 19.1$ to $25.8(\mathrm{n}$ $=80, \%=80), 25.8$ to $27.3(\mathrm{n}=7, \%=7), 27.3$ to $32.3(\mathrm{n}=2, \%=2)$ and $>32.3(\mathrm{n}=0, \%=0)$.

Mean and SD scores for weight in patient group $(\mathrm{M}=3.22, \mathrm{SD}=1.58)$. Number and percentage of weight in patient group up to $50(\mathrm{n}=22, \%=22), 51$ to $55(\mathrm{n}=6, \%=6), 56$ to $60(\mathrm{n}=34, \%=34), 61$ to $65(\mathrm{n}=13, \%=13), 66$ to $70(\mathrm{n}=16, \%=16)$ and above $70(\mathrm{n}=9, \%=9)$. Mean and SD scores for weight in control group $(\mathrm{M}=3.12, \mathrm{SD}=1.15)$. Number and percentage of weight in control group up to $50(\mathrm{n}=4, \%=4), 51$ to $55(\mathrm{n}=24, \%=24), 56$ to $60(\mathrm{n}=42, \%=42), 61$ to $65(\mathrm{n}=20, \%=20), 66$ to 70 $(\mathrm{n}=5, \%=5)$ and above $70(\mathrm{n}=5, \%=5)$.

Medical condition also affects women with preeclampsia $60 \%$ women reported that they are having other illness, $19 \%$ women reported that they have problem of diabetes, $45 \%$ women reported hypertension, $16 \%$ thyroid disease, $27 \%$ UTI, $9 \%$ kidney problem and $7 \%$ reported blood related disorder this show that it may affect preeclampsia.

Table:3

\begin{tabular}{|c|c|c|c|c|c|c|c|c|}
\hline \multirow[t]{2}{*}{ Variables } & \multicolumn{4}{|c|}{ Patient $(N=100)$} & \multicolumn{4}{|c|}{ Control $(N=100)$} \\
\hline & $\bar{N}$ & $\%$ & $M$ & $S D$ & $\bar{N}$ & $\%$ & $M$ & $S D$ \\
\hline \multicolumn{9}{|l|}{$\mathrm{BMI}\left(\mathrm{kg} / \mathbf{m}^{2}\right)$} \\
\hline$<19.1$ & 11 & 11.0 & & & 1 & 1.0 & & \\
\hline $19.1-25.8$ & 49 & 49.0 & & & 80 & 80.0 & & \\
\hline $25.8-27.3$ & 16 & 16.0 & 2.53 & 0.98 & 7 & 7.0 & 2.12 & 0.46 \\
\hline $27.3-32.3$ & 24 & 24.0 & & & 2 & 2.0 & & \\
\hline$>32.3$ & 00 & 00 & & & 0 & 00 & & \\
\hline \multicolumn{9}{|l|}{ Weight } \\
\hline Up to 50 & 22 & 22.0 & & & 4 & 4.0 & & \\
\hline $51-55$ & 6 & 6.0 & & & 24 & 24.0 & & \\
\hline $56-60$ & 34 & 34.0 & 3.22 & 1.58 & 42 & 42.0 & 3.12 & 1.15 \\
\hline $61-65$ & 13 & 13.0 & & & 20 & 20.0 & & \\
\hline $66-70$ & 16 & 16.0 & & & 5 & 5.0 & & \\
\hline Above 70 & 9 & 9.0 & & & 5 & 5.0 & & \\
\hline \multicolumn{9}{|l|}{ Medical condition } \\
\hline Any other illness & 60 & 60.0 & & & - & - & & \\
\hline Diabetes & 19 & 19.0 & & & - & - & & \\
\hline Hypertension & 45 & 45.0 & & & - & - & & \\
\hline Thyroid disease & 16 & 16.0 & & & - & - & & \\
\hline UTI & 27 & 27.0 & & & - & - & & \\
\hline
\end{tabular}


Kidney problem $\quad 9 \quad 9.0$

Blood related disorder $\quad 7 \quad 7.0$

3 Past history, present illness, comorbidity, routine check up and treatment related informations of women having preeclampsia

For detail information of the patient we can take responses on past history, present illness, comorbidity, routine checkup and on their treatment.(show in Table 3). We can ask different question relevant to the preeclampsia. On past history responses of the subject (patient with preeclampsia) was "fear due to convulsion in last pregnancy" 11 participant out of hundred response yes, "still birth of previous baby" two responses on yes, "any prolonged illness" 16 participated say yes, "past history of abortion" 15 participant say yes, "menstrual history" 23 participant say yes, "miscarriage of first baby" 19 participants say yes, "troublesome delivery" 6 participants say yes, "twins pregnancy" 5 participants reported yes and "cesarean delivery" 2 participants say yes.

Table 4: Responses of the subject on past history, present illness, comorbidity, routine check up and their treatment

\begin{tabular}{|c|c|c|}
\hline \multirow[t]{2}{*}{ Variable } & \multicolumn{2}{|c|}{ Patient } \\
\hline & Yes & $\%$ \\
\hline \multicolumn{3}{|l|}{ Past history } \\
\hline Fear due to convulsion in last pregnancy & 11 & 11 \\
\hline Still birth of previous baby & 2 & 2 \\
\hline Any prolonged illness & 16 & 16 \\
\hline Past history of abortion & 15 & 15 \\
\hline Menstrual irregularities & 23 & 23 \\
\hline Miscarriage of first baby & 19 & 19 \\
\hline Troublesome delivery & 6 & 6 \\
\hline Twins pregnancy & 5 & 5 \\
\hline Cesarean delivery & 2 & 2 \\
\hline \multicolumn{3}{|l|}{ Present illness } \\
\hline Preeclampsia related problem & 75 & 75 \\
\hline Panic due to high blood pressure & 92 & 92 \\
\hline High level of Proteinuria & 90 & 90 \\
\hline Edema on hands, face and feet. & 96 & 96 \\
\hline Headaches and nausea complaint & 80 & 80 \\
\hline Fear and anxiety related to family support. & 62 & 62 \\
\hline Constant pain above naval & 19 & 19 \\
\hline \multicolumn{3}{|l|}{ Comorbidity } \\
\hline Any other illness other than preeclampsia & 60 & 60 \\
\hline Diabetes & 19 & 19 \\
\hline Blood pressure & 45 & 45 \\
\hline Thyroid disease & 16 & 16 \\
\hline Kidney problem & 9 & 9 \\
\hline Blood related disorder & 7 & 7 \\
\hline Urinary tract infection & 27 & 27 \\
\hline
\end{tabular}




\section{Routine check up}

Facility for routine check up

Family support during routine checkup.

59

37

Treatment

Magnesium sulphate

Diazepam

Methyldopa

Depin

$\begin{array}{ll}59 & 59 \\ 37 & 37 \\ & \\ 00 & 100 \\ 97 & 97 \\ 97 & 97 \\ 97 & 97\end{array}$

On present illness responses of the subject (patient with preeclampsia) on "preeclampsia related problem" 75 reported yes, "panic due to high blood pressure" 92 responses yes, "high level of proteinuria "96 reported yes, "edema on hands, face and feet" 80 reported yes, "headache and nausea complaint" 62 reported yes, "fear and anxiety related to family support" 62 responses on yes and "constant pain above the naval" 19 reported yes out of 100

On comorbidity responses of the subject (patient with preeclampsia) was "any other illness other than preeclampsia"60 says yes, "Diabetes" 19 say yes, "blood pressure" 45 say yes, "thyroid disease" 16 reported yes, "kidney problem" 9 reported yes, "blood related disorder" 7 say yes and on "Urinary tract information 27 reported yes.

On routine checkup responses of the subjects (women with preeclampsia) was "facility for routine checkup" 59 reported yes and 41 reported no, and on "Family support during routine checkup' 37 reported yes and 63 reported no.

On treatment subject responses (women with preeclampsia) "magnesium sulphate" for management 100 says yes, "diazepam" 97 responses on yes, Methyldopa" 97 responses on yes and "depin" 97 say yes.

\section{RESULTS AND DISCUSSION}

The main motive of the study to know the prevalence of depression in women with preeclampsia in order to grasp the attention of health care system by monitoring such psychological issues and help them to deal with burden of depression and anxiety and help them in reducing complication during pregnancy. Data were obtained from pregnant women with preeclampsia and pregnant women without preeclampsia. In order to understand the relationship, One way ANOVA was used, on the scores obtained on the dimension of depression measures.

\section{Table 1}

Mean scores, SD and F Value to show the level of depression in groups of patient with preeclampsia and normal pregnant women.

\begin{tabular}{lllll}
\hline Variables & $\boldsymbol{N}$ & $\boldsymbol{M}$ & $\boldsymbol{S D}$ & $\boldsymbol{F}(\mathbf{1}, \mathbf{1 9 8})$ \\
\hline Depression & & & & \\
Patient & 100 & 2.02 & 0.35 & \\
Control & 100 & 0.91 & 0.34 & $517.72 * *$ \\
\hline
\end{tabular}

$* * P<.01$. 


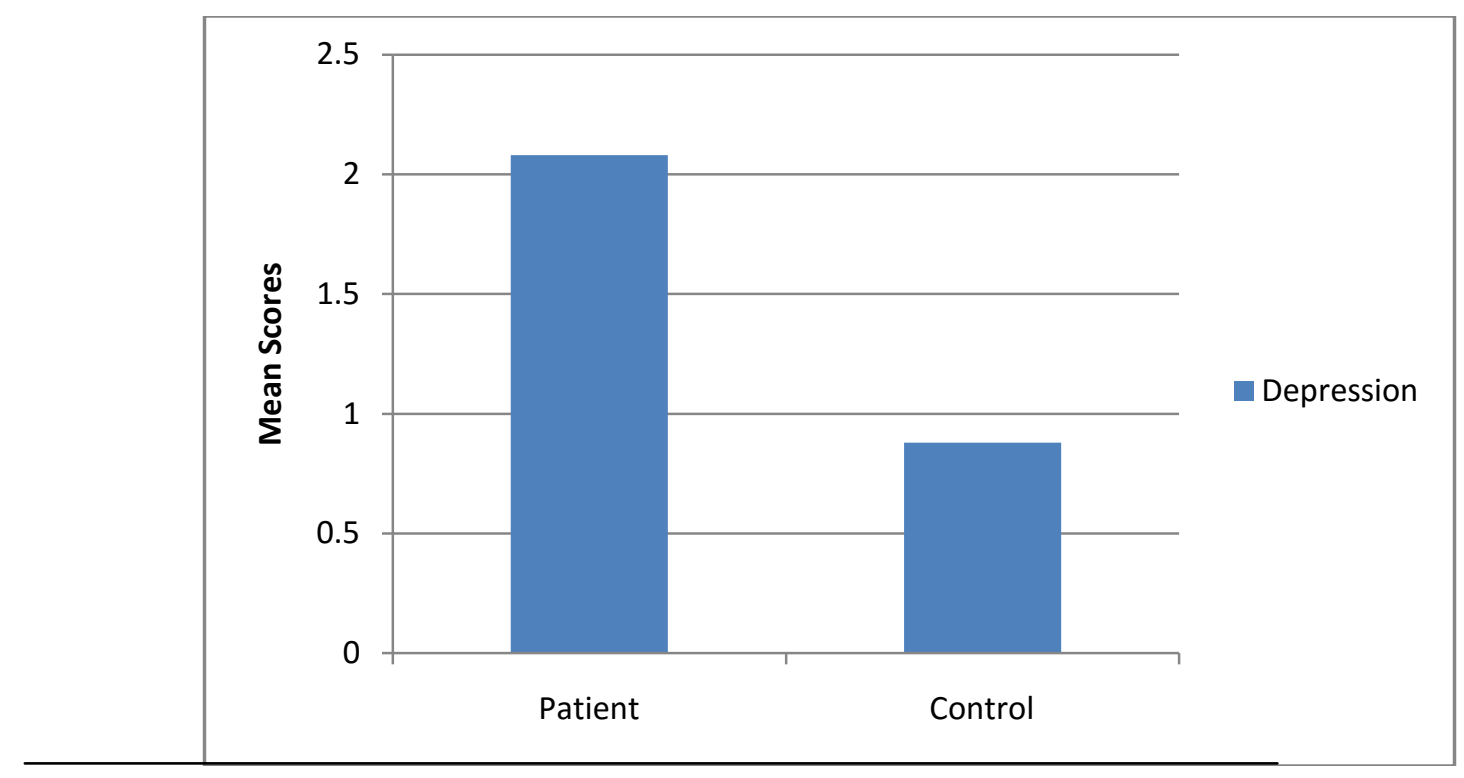

Figure 1. Mean score of groups on the level of depression

To examine the relationship between groups on the level of depression, one way ANOVA was used. A summary of between group analysis of variance for the measures of depression shown in table 1 , that revealed a significant relationship between groups and level of depression, $F(1,198)=517.72, p<$ .01 , Mean scores indicated that women with preeclampsia $(M=2.02, S D=0.35)$ had higher level of depression in comparison to control Group $(M=0.91, S D=0.34)$. The figure no 1 also show that the level of depression was found more in patient group in compare to control group.

\section{CONCLUSION}

In the present research finding the level of depression was more in patient group in compare to control group.

\section{REFERENCES}

1. American College of Obstetricians and Gynecologists Committee on Obstetric Practice. (2002). Diagnosis and management of preeclampsia and eclampsia. International Journal of Gynecology and Obstetrics, 77, 67-75.

2. Arck, P.C. (2001). Pregnancy loss. American Journal of Reproductive Immunology, 45, 303-309.

3. Austin, M.P.V. (2003). Psychosocial assessment and management of depression and anxiety in pregnancy. Australian Family Physician, 32(3), 119-120, 122-126.

4. Bennett, H.A., Einarson, A., Taddio, A., Koren, G., \& Einarson, T.R. (2004). Prevalence of depression during pregnancy: Systematic review. Obstetric and Gynecology, 103, 698-709.

5. Buist, A E. (2002). Mental health in pregnancy: the sleeping giant. Australasian P ychiatry, 10(3),203-206.

6. Buist, A.E., Milgrom, J., Morse, C., Durkin, S., \& Rolls, C. (2000). Integrating services in the recognition and management of postpartum depression. Australian Journal of Primary Health Interchange, 6(3-4), 74-79.

7. Burt, V.K., \& Stein, K. (2002). Epidemiology of depression throughout the female life cycle. Journal of Clinical Psychiatry, 63(SuppI7), 9-15.

8. Chung, T.K., Lau, T.K., Yip, AS., Chiu, H.F., \& Lee, D.T. (2001). Antepartum depressive symptomatology is associated with adverse obstetric and neonatal outcomes. Psychosomatic Medicine, 63(5), 830-834. 
9. Evans, J., Heron, J., Francomb, H., Oke, S., \& Golding, 1. (2001). Cohort study of depressed mood during pregnancy and after childbirth. British Medical Journal, 323, 257-260.

10. Kurki, T., Hiilesmaa, V., Raitasalo, R., Mattila, H., \& Ylikorkala, O. (2000). Depression and anxiety in early pregnancy and risk for preeclampsia. Obstetric and Gynecology, 95, 487490.

11. Kurki, T., Hiilesmaa, V., Raitasalo, R., Mattila, H., \& Ylikorkala, O. (2000). Depression and anxiety in early pregnancy and risk for preeclampsia. Obstetric and Gynecology, 95, 487-490.

12. National High Blood Pressure Education Program (2000). Working Group Report on High Blood Pressure in Pregnancy. Md: National institutes of health; NIH publication No. 00- 3029.

13. Nonacs, R., \& Cohen, L.S. (2002). Depression during pregnancy: Diagnosis and treatment options. Journal of Clinical Psychiatry, 63(7), 24-30.

14. O'Hara, M.W., \& Swain, AM. (1996). Rates and risk of postpartum depression-a meta analysis. International Review of Psychiatry, 8, 37-54.

15. Pschirrer, ER., \& Monga, M. (2000) Risk factors for preterm labour. Clinical Obstetrician and Gynecology; 43(4), 727-734.

16. Sugiura-Ogasawara, M., Furukawa, T.A., Nakano, Y., Hori, S., Aoki, K., \& Kitamura, T. (2002). Depression as a potential causal factor in subsequent miscarriage in recurrent spontaneous aborters. Human Reproduction, 17(10),2580-2584.

17. Texeira, J.M.A., Fisk, N.M., \& Glover, V. (1999). Association between maternal anxiety in pregnancy and increased uterine artery resistance index: cohort based study. BMJ, 318,153-157.

18. Wisner, K.L., Zarin, D.A., Holmboe, E.S., Appelbaum, P.S., Gelenberg, A.J., Leonard. H.L. et a1. (2000). Risk benefits decision making for treatment of depression during pregnancy. American Journal of Psychiatry, 157(12), 1933-1940.

19. WHO: The World Health Report 2005: Make every mother and child count. Geneva, Geneva, World Health Organisation, 2005.

20. Zuckerm\%U1, B., Amaro, H., Bauchner, H., \& Cabral, H. (1989). Depressive symptoms during pregnancy: Relationship to poor health behaviors. American Journal of Obstetric and Gynecology, 160(5 Pt 1), 1107-1111.

21. Zuckerman, B., Amero, A., Bauchner, H. \& Cabral, H. (1989). Depressive symptoms during pregnancy: relationship to poor health behaviours. American Journal of Obstetrics and Gynaecology, J 60(5), 1107-1111. 